\title{
USE OF 3D TECHNOLOGIES WITHIN THE CONSERVATION OF THE ANCIENT WINDOWS OF THE BASILICA OF S. SABINA IN ROME. CONSTRUCTION OF EXHIBITION STANDS IN CARBON COMPOSITE ON A MILLED STRUCTURE.
}

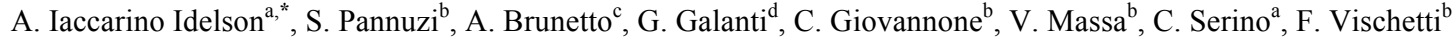 \\ ${ }^{a}$ Equilibrarte srl, 00179 Rome, Via Centuripe 34, Italy - info@equilibrarte.it \\ ${ }^{\mathrm{b}}$ Istituto Superiore per la Conservazione e il Restauro, 00153 Rome, via di San Michele 25, Italy - (simona.pannuzi, carla.giovannone, \\ valeria.massa, flavia.vischetti)@beniculturali.it \\ ${ }^{\mathrm{c}}$ Restauri Brunetto, 36100 Vicenza, Italy - annalaser@alice.it \\ ${ }^{\mathrm{d}}$ Fabrica Conservazione e Restauro scpl, 00138 Roma, Via Ludovico da Casoria 11, Italy - fabricascpl@gmail.com
}

KEY WORDS: 3-D milling, 3-D modeling, exhibition stands, carbon fiber composite, laser cleaning, fragmented artifact, counterforms, restoration.

\begin{abstract}
Rare and precious window elements from the Paleochristian Basilica of Saint Sabina in Rome, made of plaster gypsum with translucent selenite used as glass for light transmission, were discovered by Antonio Muñoz during the restoration of the building at the beginning of the 20th c. Originally standing within the stone window frame, were then mounted on wood planks with screws for holding together the scattered fragments. The surfaces were covered with grime and the selenite elements were blinded by the wooden supports.

During the recent conservation treatment at ISCR, traces of Egyptian blue on the internal surfaces were detected. Cleaning with laser allowed their conservation and the removal of gypsum deposits from the fragile selenite.

3-D scanning was performed for milling, out of polystyrene blocks, the counterforms that were needed for turning the artifacts upside down. After cleaning and re-assembling of the fragments, a new 3-D scan was performed to obtain a complete model of the artifacts that was used to define the best orientation of the windows, both for exhibition purposes and for the distribution of the weight-related stresses.

Following a project based on 3-D modeling, exhibition stands were produced with a core material milled out of PET foam, reinforced with outer skins made with carbon fiber adhered under vacuum to the core material with epoxy resin. The new exhibition stands, very light and rigid, permit all-round appreciation of the artifacts and allow the light to shine through the selenite elements.
\end{abstract}

\section{Introduction}

The stucco window-transennas of Santa Sabina in Rome have been found in situ during the restorations of Antonio Muñoz in 1914-1919 ${ }^{1}$. The ancient windows that illuminated the central nave and the apse of the building, were probably realized during the papacy of Sisto $\mathrm{V}$. They had probably been in continual use at least until 1690, when G. Giustino Ciampini refers to them in his description of the basilica. Muñoz had the windows closed with new transennas, still visible, in reinforced concrete mixed with marble dust and with new sheets of natural selenite, reproducing "the original drawings found in the site" ${ }^{2}$. The original transenna elements were removed from the walls by Muñoz, placed on wood boards and blocked by many iron screws, piercing the thickness of the stucco. These boards were affixed on the wall of the church portico, where they remained until a few years ago, when, during general works of rearrangement, they were further dismembered, recovered in wood cases and preserved in the depot of the Dominican Museum of Santa Sabina, recently realized inside the monastery near the church $^{3}$.

Although in the first time Muñoz accepted the hypothesis that the transennas could be attributable to the original building of the $\mathrm{V}$ century ${ }^{4}$, then he rejected this chronology because the

\footnotetext{
${ }^{1}$ MUÑOZ 1916, 8; MUÑOZ 1919, 18, 27-30; MUÑOZ 1938, 16, 29-33; BELLANCA 1999, 14, 17-19, 35-36.

${ }^{2}$ MUÑOZ 1938, pp.29-33.

${ }^{3}$ ARAMINI et al. 2016, 397-398.

${ }^{4}$ Instead, Richard Krautheimer in his architectural study on Santa Sabina, believed that the stucco transennas discovered by Muñoz were coherent with the large arch-windows of the
}

transennas were made with "unrefined work and poor material". Therefore Muñoz attributed the transennas to the restoration made in the church during the "dark ages" of the Early Middle-Ages by Pope Leone III (795-816), who remade the windows inside the Basilica of S. Paolo and S. Giovanni in Laterano "(fenestras...) ex metallo gypsino (decoravit) $»^{5}$, or by Eugenio II $(824-827)^{6}$.

original building and for this reason he dated them in the $\mathrm{V}$ century (KRAUTHEIMER, 1976, pp. 86-87).

${ }^{5}$ LIB. PONT. II, 9, 10, 13.

${ }^{6}$ MUÑOZ 1938, 31-32. See also: TRINCI, 1976, 224-227; BUTTICI, 1976; PASQUINI, 2002, 80-81. But we must observe that, even if the patterns of the transennas from Santa Sabina are similar to those of the Early Medieval church of Santa Prassede, the latter are small arch-windows, as it was typical at that time. Those of Santa Sabina were instead part of very large windows, as it was characteristic in Paleochristian churchs. So, we can hypothesize that the patterns, already used in the Roman Age, e.g. for the fences (see the reliefs of Costantino's Arch and the reliefs of the basis of the Teodosius's Obelisk in Istanbul, and many other examples of fences conserved in Roman archaeological sites, as Foro Romano, Palatino in Rome and many others), were still used for making transennas also in the centuries of the Early Medieval Ages. However, although we accepted the traditional dating to the Early Middle Ages for the surviving plaster transennas, the question of how the large windows of the first Christian buildings could be closed remains unanswered. And it is strongly presumable the hypothesis of a continuity in the use of this type of artifacts from the LateAntiquity to the following centuries of the Middle Ages, without particular transformations of the decorative patterns, 
The conservation treatment and research carried out at ISCR initially involved only two of the several elements of transennas, these were composed of two parts (with diamond, "cancellum", wheel and arches patterns) joined by Muñoz on the same wood board. It is impossible to understand if these elements belong to one or more window-transennas. In the composition made by Muñoz inside the portico of the church, there were other elements connected with them, currently undergoing restoration at ISCR. The careful examination of the surfaces and a series of diagnostic investigations, made possible to do some hypothesis about the procedure, the technique and materials used for making them. During the restoration work it has been verified that all elements were made of wooden moulds with various decorative patterns, in which was spread out the chalky dough in two layers, among which were inserted the plates of selenite ${ }^{7}$.

A series of diagnostic investigations were carried out: stratigraphic sections analyzed with optical microscopes and with SEM-EDS, thermo-gravimetric analysis (TGA); microFTIR $^{8}$. A particularly interesting result has been obtained by the observation with the VIL on the superficial finishing of one side of all transennas, better conserved and presumably the side that looked into the church ${ }^{9}$ : on the surface borders of the transennas some areas of luminescence, which became more evident after the Laser cleaning. Some samples were further investigated with SEM-EDS in stratigraphic section, showing blue pigmented grains, identified as Egyptian blue. VIL and SEM-EDS showed the presence of Egyptian blue on all the other elements of transennas conserved in the depot of Santa Sabina ${ }^{10}$.

\section{Description of the artifacts and of their conservation problems.}

Having been found in the early $20^{\text {th }}$ century by Muñoz, hidden between two walls of the basilica, they were at the time in very poor condition and highly fragmented. During that intervention, they were reassembled on wooden planks with gypsum and held in place with iron screws through holes drilled in the more robust areas of the original material. The planks also served as display stands, as they were hanged to the walls of the narthex. This choice impeded the perception and the understanding of the original function of the transennas, hindering any source of light from the rear.

The position in which the fragments were assembled proved to be in some points mistaken, the gypsum often covered ample areas of the original surfaces. Furthermore, such display and conservation choices were the fruit of an interpretation of the artifacts that only allowed considering them with curiosity. As a matter of fact they were regarded mostly as the evidence on which Muñoz's choice was based, of having the new windows of the basilica made in that specific shape and materials.

For the present fruition, this condition was incompatible with the appreciation of their manufacturing techniques and

among which the traditional roman theme "a cancellum" was the most used. The wood samples from the beams of the ancient windows, on which Carbon-14 investigations are being carried out in the laboratory CEDAD of the University of Lecce, may help providing a more precise dating.

${ }^{7}$ ARAMINI et al. 2016, 396-397.

${ }^{8}$ ARAMINI et al., 2016; PANNUZI et. al. 2015, 156.

${ }^{9}$ VERRI, 2008, 41-50; ARAMINI, 2013, 20-24.

${ }^{10}$ PANNUZI, 2015, 156-157; ARAMINI, 2016. aesthetic qualities. Even a real understanding of their function was limited, as the very peculiar and specific translucency of the selenite crystals was hidden by the opaque structure and by the presence of thick depositions of mortars and grime (figure 1).

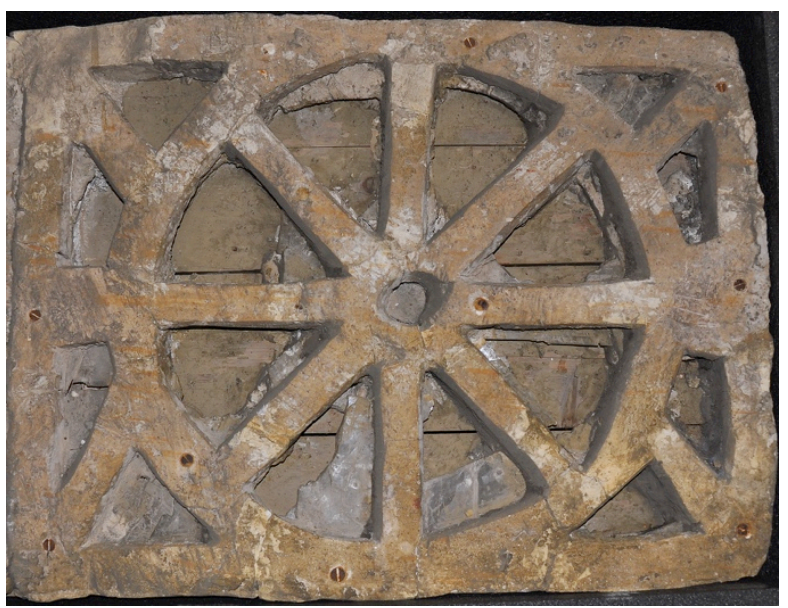

Figure 1. One of the elements as found after Muñoz's intervention.

Following these considerations and because of the poor condition in which the artifacts and the wooden planks were found, a thorough conservation intervention was considered necessary and offered an opportunity to conserve and display these precious objects with an approach more adequate to the present culture and priorities.

The separation from the wooden structures required complex handling, because of the overall weight, the fragility of the transennas and the unevenness of their surface. These conditions would not allow turning them over safely without a counterform, needed to distribute the weight on the entire surface releasing dangerous out-of-plane stresses from the original materials. The counterforms would also become useful to avoid uncontrolled displacement of the fragments during the removal of the wooden structures from the rear.

Traditional approaches proposed making a counterform with gypsum or foams (such as polyurethane) directly on the artifact through a protective plastic sheet. A first attempt was done with gypsum, resulting in a very heavy structure that made the mere action of turning the artifact over become a complex achievement.

The decision was made to use a new approach, based on 3D technologies, for the counterforms and for the design and construction the new display stands. This choice allowed to produce the temporary supports and exhibition stands that match the conservation needs of the artifacts.

\section{3-D milling of polystyrene counterforms and removal of Muñoz additions.}

A preliminary 3-D scan was performed in order to obtain a digital model for the shape the transennas had acquired after the last intervention and through their following conservation history. This operation was performed with an optical 3-D scanner, GOM Atos. The 3-D image is a precious source of information for documentation purposes and provided a Stereo Lithography interface (.stl) file for 3-D modeling of the counterforms. 
The negative image of the front of the artifacts was used to generate a virtual block modeled ${ }^{11}$ so as to avoid any contact of the counterform on the extremely fragile selenite elements, that wouldn't have been able to withstand any pressure. Such modeling of the counterform would have been much more complex and risky with traditional techniques, as it would have involved physical contact with the selenite elements.

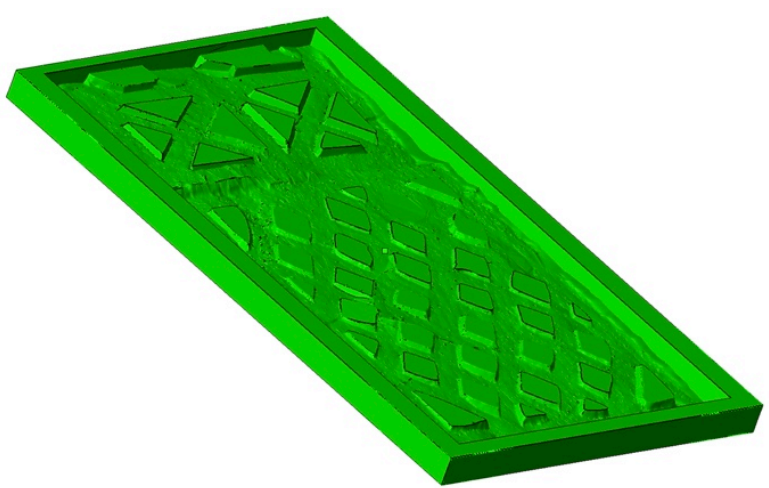

Figure 2. The 3-D model for one of the counterforms.

The counterforms were milled ${ }^{12}$ out of $10 \mathrm{~cm}$ thick blocks of polystyrene, a soft material that was judged adequate for (at least short term) contact with the artifacts' surface.

The removal of the wooden planks started by unscrewing from the front the few screws that were not completely blocked with oxidation. Thereafter, the counterforms were placed on the transennas and fastened with straps to the wooden planks before turning the sandwich upside down in order to work on the rear. The blocked screws were removed by carefully demolishing the surrounding wood with electrical and hand driven tools, imposing as little vibration as possible.

Once the original elements where freed, they were numbered and their position documented. All loose fragments were removed, and gradually all the previous joining with thick layers of gypsum was disassembled. This led to a first level of cleaning, which involved removal of all improper materials from fracture surfaces for the determination of better connection between them and reorganize those fragments that had been improperly arranged.

\section{Cleaning with laser and connecting the fragments.}

After preliminary tests with mechanical and chemical methods for cleaning the surfaces, it became clear that laser beams allowed to work fast enough with the great advantage of minimizing the quantity of water implied in the process. Both the original gypsum based mortar and the selenite elements risked to be affected by water solutions, while laser instruments allowed to remove in a controlled and selective manner superposed the gypsum based layers ${ }^{13}$. On the

\footnotetext{
${ }^{11}$ Scanning and modeling was performed by Danilo Salzano, Measure 3D, using Rhinoceros (Mcnell and associates) and Geomagic Studio (3D Systems).

123 axis 3-D milling machine with a working area of 2800x1800x140 mm, Equilibrarte srl, Rome.

${ }^{13}$ Cleaning of the stucco was carried out with two laser beams. Nd:YAG ( $\lambda 1064 \mathrm{~nm})$ : 'Eos1000LQS' and 'Eos Combo', used in the mode LQS (120 ns) with fluence
}

selenite, these layers seemed to be due to the solubilization and secondary recrystallization of the surrounding materials in humid environment.

The residual particles of Egyptian blue suggested that the whole window was what originally painted in a hue of blue though hardly any visible trace could be detected with naked eye observation. The same VIL photoluminescence imaging where repeated after laser cleaning, confirming that the Egyptian blue was not affected nor deteriorated during the process. On the contrary, after cleaning a larger number of particles was detected.

Treatment of the delicate selenite elements was object of a specific study ${ }^{14}$, aiming at recovering their transparency without causing them further damage. During cleaning, it was necessary to work on both sides of the artifact, looking at it with transmitted light.

The critical problem of the reassembling of the fragments became the need of a project once all the fragments had been cleaned and the joining surfaces freed. Muñoz's proposals of assembly was critically revised and verified, showing that a few fragments had been misplaced. It was also clear that the adhesive they used had produced an exceeding distance between the fragments, impeding their correct alignment. A thorough revision of their position allowed understanding that it would have been possible to reassembling the transennas with an almost complete reconstruction of their original form, as only marginal parts had to be integrated. During this phase of the work, the feasibility was confirmed of the project to exhibit them in a vertical position with exhibition stands that would allow to appreciate the translucency of the selenite elements.

The bond between the fragments needed to be strong enough for safe handling of the rather heavy original materials. The decision was made two glue them with epoxy resin, after treating the surfaces with an acrylic resin ${ }^{15}$ to work as a local consolidant, in order to reduce the risk of peeling, and as a coating for reversibility purposes. The very fluid aliphatic epoxy $\operatorname{resin}^{16}$ was turned into a thixotropic paste with the addition of fumed silica ${ }^{17}$. As a matter of fact, the complexity of the joining process required working simultaneously on many fractures with irregular shapes and often with large gaps that need to be bridged over (figure 3). Reaching a rather thick paste consistency and a very thixotropic behavior ensured the adhesive to be worked with a spatula and would not flow after application. between 2 and $2,4 \mathrm{~J} / \mathrm{cm}^{2}$, carefully wetting the surface with water mist right before. Cfr. ARAMINI et alii 2016.

${ }^{14}$ Cleaning of the selenite has been done with laser Nd: YAG using the secondary harmonic $(\lambda 532 \mathrm{~nm})$ in the Q-Switched ( $8 \mathrm{~ns}$ ) with fluence between 0,54 and $0,80 \mathrm{~J} / \mathrm{cm}^{2}$. Cfr. ARAMINI et alii 2016.

${ }^{15}$ Application of Paraloid B72 was done in a sequence of increasing concentrations $(5 \%, 7 \%$ e $10 \%)$ with the goal of obtaining some consolidation under the surface. This was deemed necessary in order to avoid the risk of exfoliation of the gypsum surface.

${ }^{16}$ RAKU-TOOL $®$ EI-2500/EH-2970-1

${ }^{17}$ Approximately 8\% w/w allows to have a "whipped cream" consistency that avoids any undesired dispersion of the adhesive. 


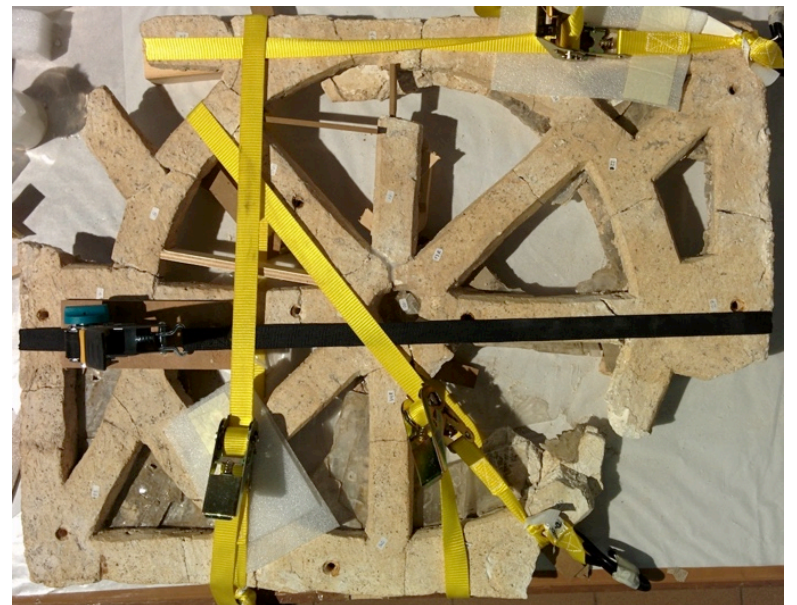

Figure 3. Gluing the original fragments in their best fitting position.

Filling of the lacunas was done with an acrylic plaster charged with glass microballoons and different stone dusts until it reached the right color and texture for matching that of the surrounding original ${ }^{18}$. This material proved suitable, not only for aesthetic reasons but also because it requires the use of very little water and because it's binder stays soluble in nonpolar solvents for reversibility ${ }^{19}$.

\section{3-D modeling of the new exhibition stands.}

A new 3-D scan of the reassembled artifacts was performed after the completion of all plastic integrations. The 3-D model was placed in the virtual space so as to stand in a vertical position, or at least with a satisfying compromise between the local inclination of the surfaces and the center of gravity.

The data was used for modeling the new exhibition stands, which have then been milled out of a foam core material and coated with carbon fiber/epoxy composite, in a sandwich structure.

The new stands have been placed on the rear of the windows, once the exterior of the basilica, more damaged and therefore preserving less information and aesthetic value. In order to hold the artifacts in position on their stand the existing holes, due to Muñoz's screws, could be used. New stainless steel screws were used to hold some of the weight and keep them upright, inserted in stainless steel threaded elements inserted in the new stands.

Modeling was done according to the following design principles:

- The space behind the selenite elements shall always remain free, in order to allow transmission of light.

- The stand will consist of rigid elements placed along the fragility lines of the artifact (where there is presence of discontinuities or other damages) so as to release dangerous stress.

\footnotetext{
18 Integrations were done with "Stucco forte Light" and mixtures of mineral charges $(1: 1 \mathrm{v} / \mathrm{v})$. The charges were: Alvito limestone, yellow brick, red pozzolana, grey pozzolana. ${ }^{19}$ This acrylic binder had already been used at ISCR for the integration of the lacunae of the detached wall paintings by Giusto de Menabuoi, after a study of its chemical and physical properties and stability to UV.
}

- $\quad$ The rigid elements will meet the position of the existing holes, as they will house the supporting screws. It will not be necessary to use all the holes and this will contribute minimizing the structures' design.

- The space available for the construction of the stand will be dimension of the section of the transenna but reduced by $5 \mathrm{~mm}$ on each side, so as to limit its visibility from the privileged point of view, corresponding to the inside of the basilica.

- The stand will interest the minimum possible surface, as necessary to obtain the rigidity necessary for conservation. Also the thickness of the stand will be kept to the minimum necessary.

The front of the stands copies the rear surface of the windows, so as to obtain a good contact and an efficient transfer of stresses.

Knowledge acquired on the ancient artifacts during the conservation treatment allowed defining the most fragile areas and the preferable directions for force distribution in the interaction with exhibition stands. This information, combined with the mapping of the screw holes, allowed evaluating different patterns of lines, aiming to the minimum surface and to a pattern that would not disturb the appreciation of the rear of the transennas, having at the same time some degree of aesthetic value.

Evaluating alternatives with the use of the 3-D modeling software was relatively rapid and, what was considered even more important, allowed considering the alternatives with the detail necessary to detect the presence of most of the possible problems (figure 4).

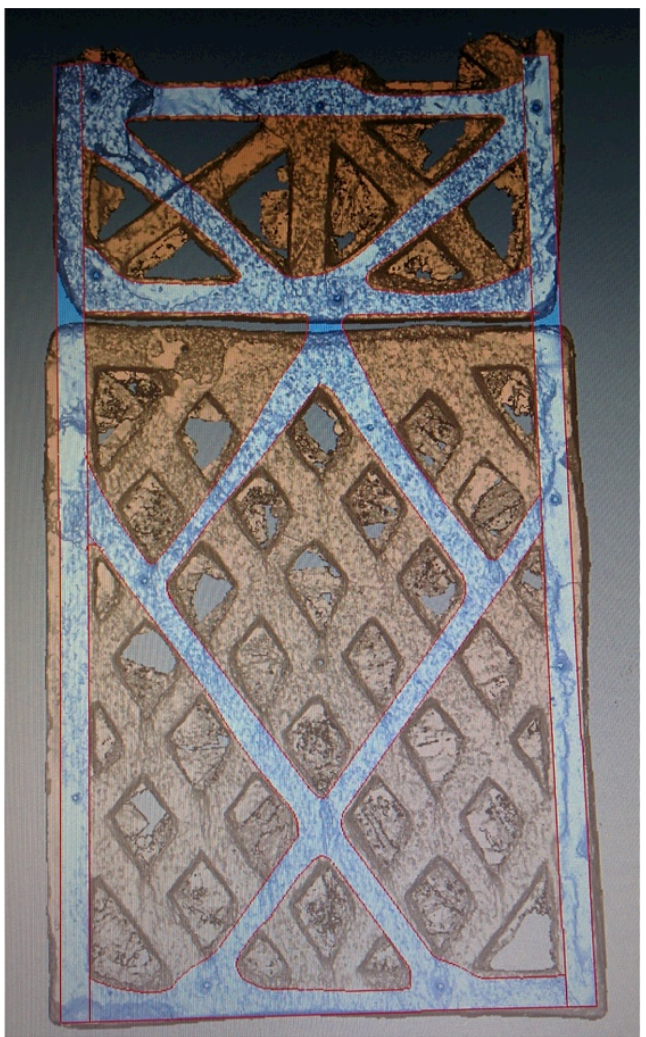

Figure 4. During the modeling of one of the exhibition stands. 
The design ended up with a simplification of the rhomboidal grid pattern for the diamond "cancellum" transenna (figure 5) and for a more "organic" shape for the wheel and arches one, following more strictly the mechanical requirements.

The minimum section for the stand was considered to be $35 \times 35 \mathrm{~mm}$ and a closed perimeter was judged useful from the static and aesthetic and points of view.

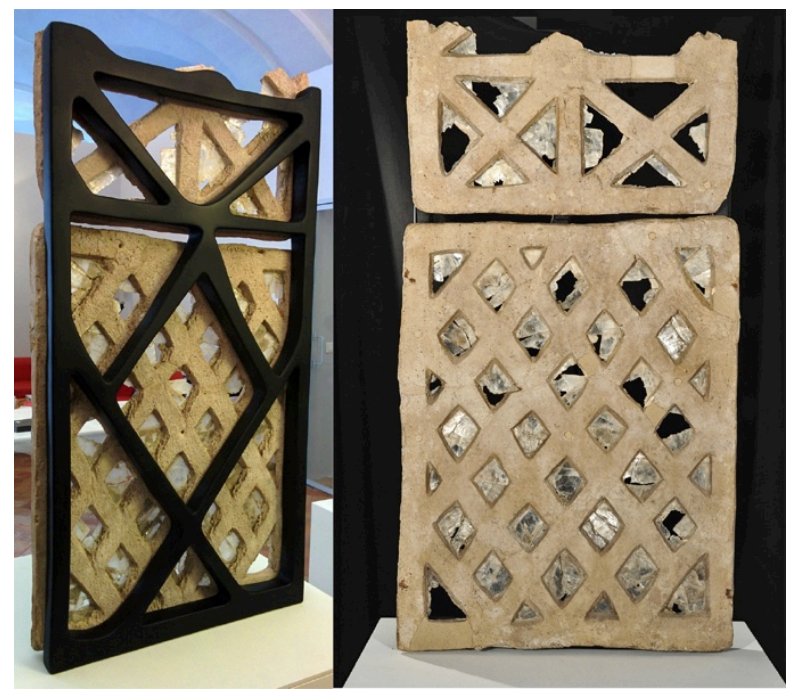

Figure 5. The "cancellum" transenna after assembly, as mounted on it's exhibition stand.

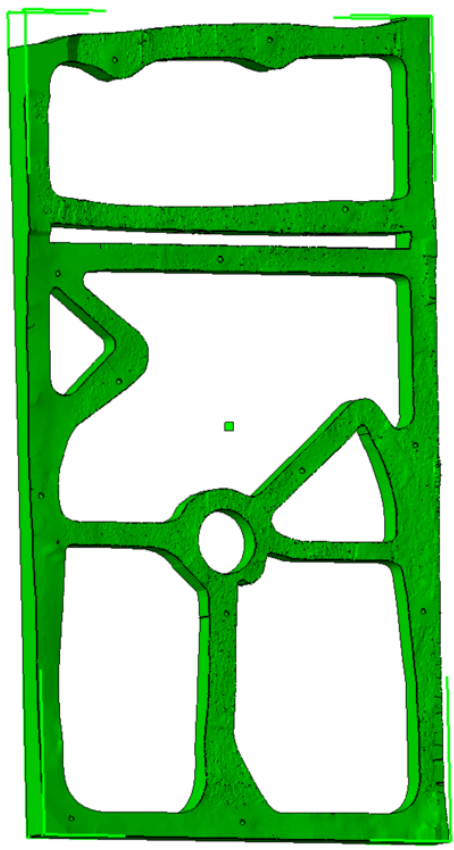

Figure 6. The milled core material conforms exactly to the rear of the transenna, contributing to an efficient transfer of stresses.

\section{The 3-D technology used for the construction of the} stands in carbon fiber composite.

The chosen design was transformed in a Stereo Lithography interface (.stl) file and, as already for the polystyrene counterforms, this was used for milling the core material. The process involved the use of a CAM software, in this case Vectric Aspire, to produce the instructions for the milling machine. Being the milling machine an Arduino driven self built "Mechmate", the tool paths were generated in a "Shapeoko" compatible format and sent to the Arduino board with the 3-D printer controlling software "Printrun".

The block of core material, a very durable PET foam ${ }^{20}$, was milled in the required shape and then physically tested on the reverse of the transennas, in order to detect any problem and do any necessary modification.

The core material was then coated with a double layer of carbon fiber textile, a $2 \times 2$ Twill weighing $416 \mathrm{~g} / \mathrm{sqm}^{21}$, with epoxy resin in a vacuum bag.

Steel threaded inserts were placed in the position for the chosen screw holes and for the connection with the exhibition base. The whole structure was finished with a polyurethane matt black varnish, in order to clearly differentiate their appearance from the transennas and obtain an easier appreciation of the artifacts.

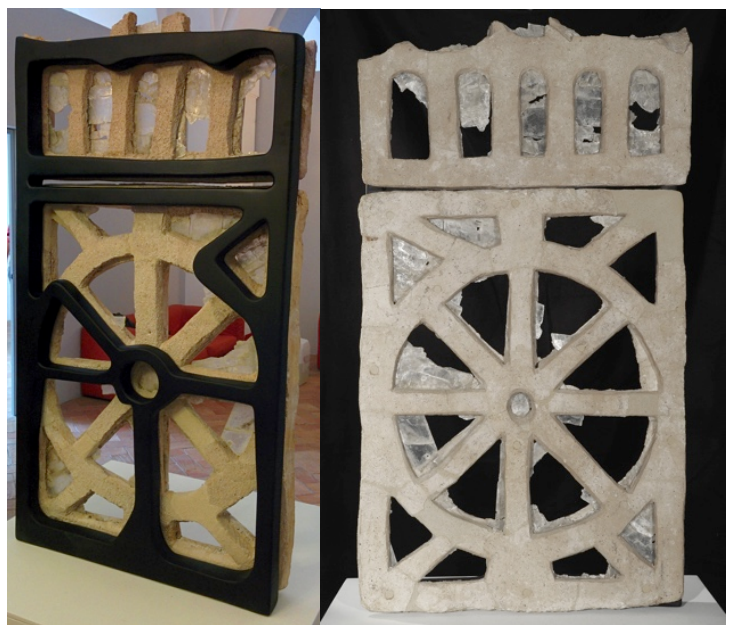

Figure 7. The "wheel" transenna after assembly, as mounted on it's exhibition stand.

\section{Conclusions.}

Without the 3-D technology the production of the exhibition stands would have been much more complex and potentially risky. A good example being the construction of the carbon fiber panels for the detached mosaics from Aqui (Rava, 2004), that required the use of the actual rear of the mosaics, on their counterform, to be used as a physical mold for the composite panel in a vacuum envelope.

3-D technologies are becoming a more and more accessible and widespread tool. They prove to be particularly suitable for solving problems related to cultural heritage, as they provide a reliable record of the form, which can be used for several levels of interaction with the unique and unrepeatable artifacts. Particularly useful is the reduction of physical interaction, what makes some procedures become much less dangerous. When, as in this specific case, a physical

\footnotetext{
${ }^{20}$ Divinylcell P 60, DIAB group, Sweden.

${ }^{21}$ HR Carbon Fiber $12 \mathrm{~K}$ - 800 tex, with RAKU-TOOL ${ }^{\circledR}$ EI2500/EH-2970-1 as epoxy resin.
} 
counterpart is needed, special attention has to be given to the techniques used: 3-D printing often generates small distortions in the printed object, while 3-D milling is less likely to generate tensions in the structure, resulting more reliable.

A recent example of 3-D milling a support structure, part of an exhibition stand, is that of the unfired clay head from Orvieto (Huber, 2016), that needed an interface with the $19^{\text {th }}$ c. marble base and was extremely fragile to handle.

Still, recent evolutions of 3-D printing (such as Selective Laser Sintering, SLS and Stereo Lithography, SLA) allow obtaining more reliable forms. A well known example, at present still on the press, is the integration of the missing head of a funerary bust from Palmyra after intentional damage caused by IS militants (The Associated Press, 2017) carried out at ISCR in February 2017.

\section{REFERENCES}

Aramini, F., Biocca, P., Brunetto, A., Conti, L., Giovannone, C., A., Massa, V., Pannuzi, S., Sidoti, G., 2014. Effects of laser radiation on hurdles in selenite gypsum and plaster from Santa Sabina in Rome. In: Atti Convegno Aplar 5, City of the Vatican.

Aramini, F., Brunetto, A., Giovannone, C., Iaccarino Idelson, A., Massa, V., Pannuzi, S., 2016. Restoration of the ancient transenne of St. Sabina Basilica in Rome: critical reading of interventions past and present. In: Atti del $32^{\circ}$ Convegno Internazionale Scienza e Beni culturali, Eresia ed ortodossia, Bressanone, 28/6 - 1/7 2016, Arcadia Ricerche srl, Venice, pp. 395-406.

Aramini, F., Santopadre, P., Sidoti, G., 2013. The identification of the Egyptian Blue in the stratigraphic sections by means of photoluminescence. In: Bollettino ISCR, n. s. 27 , Rome, pp. $20-24$

Arbace, L., Sonnino, E., Callieri, M., Dellepiane, M., Fabbri, M., Iaccarino Idelson, A., Scopigno R., 2012. Innovative uses of $3 \mathrm{D}$ digital technologies to assist the restoration of a fragmented terracotta statue. In: Journal of Cultural Heritage 2012. http://dx.doi.org/10.1016/j.culher.2012.06.008

Bellanca, C., 1999. The basilica of Santa Sabina and speeches by Antonio Munoz, Romae : In Conventu Santa Sabinae, Rome pp. 14,17-19, 35-36.

Duchesne, L., 1982. Liber pontificalis, II, Paris, pp. 9, 10, 13.

Buttici, G., Rosario, G., 1976. St. Sabina, St. Prassede and St. Giorgio al Velabro. In: Rome and the Carolingian age, Atti delle giornate di Studio, Rome.

Giovannone, C., Ozino Caligaris, E., Scarpitti, P., D’Agostino,L., Aramini, F., Bartolini, M., Sidoti,G., Torre, M., 2015. A particular filler to the detached wall paintings by Giusto De 'Menabuoi of the Baptistry of Padua Cathedral, In: Atti del XIII Congresso Nazionale IGIIC "Lo Stato dell'Arte", Centro Conservazione e Restauro La Venaria Reale, Turin
Huber, E., Iaccarino Idelson, A., Serino, C., Canistrà, A. The restoration of a work of art suffered badly: the head of the clay model of the statue of St. Thomas from the Cathedral in Orvieto. In: XIV Congresso Nazionale IGIIC, 1'Aquila 2016

Iaccarino Idelson, A., Serino, C., 2011. Design and implementation of the support structure for the sculpture fragments. In: L. Arbace, Sonnino, E., Madonna of Pietranico. History, restoration and reconstruction of terracotta work, Edizioni Zip, Pescara, pp. 83-87.

Krautheimer, R., Corbett, S., Frank, W., 1976. Corpus basilicarum christianarum Romae : the ancient Christian basilicas of Rome (4.-9.), Vol. 4, Istituto di archeologia cristiana, City of the Vatican, pp. 86-87

Muñoz, A., 1916. Studies on the Roman basilica of Santa Sabina and St. Prassede / dissertation read in the Pontifical Roman Academy of Archeology from the corresponding member prof. Antonio Muñoz March 30, 1916, Rome, p.8.

Muñoz, A., 1919. Baroque Rome, Bestetti \& Tumminelli, Rome, pp. 18, 27-30

Muñoz, A., 1938. The restoration of the Basilica of Santa Sabina / Antonio Munoz; with a foreword by Fr. Martin S. Gillet O. P, Palombi, Rome, pp. 16,29-33

Pannuzi, S., Aramini, F., Conti, L., Giovannone, C., A., Massa, V., Sidoti, G., 2015. Architectural elements of early medieval stucco in Rome and Lazio: transenne of window of Santa Sabina on the Aventino. In: VII Congresso Nazionale di Archeologia Medioevale, Società degli Archeologi Medievisti Italiani, Palazzo Turrisi, Lecce, 9-12 Settembre 2015, Lecce, pp. 153-157.

Pasquini, L., 2002. The decoration in stucco in Italy from Late Antiquity and the Middle Ages, Longo, Ravenna, pp. $80-81$.

Rava, A., Fratini, F., Iaccarino Idelson, A., Serino, C., Pagella, E., Restoration of the Cathedral of Acqui mosaics, preserved in the Civic Museum of Ancient Art, Palazzo Madama, Turin. In: Atti del Congresso dell'International Institue for Conservation Italian Group, Genova Palazzo Reale 27-29 Settembre 2004, Genova

The Associated Press, 2017. Italian teams restore damaged busts from ancient Syrian city Italy, Rome. https://phys.org/news/2017-02-italian-teams-ancient-syriancity.html (16 February 2017)

Trinci Cecchelli, M., 1976. 7.4: The first ecclesiastical region, In: Corpus della scultura medioevale, Centro italiano di studi sull'alto Medioevo, Spoleto, pp. 224-227.

Verri, G., 2008. The used and distribution of Egyptian Blue: a study by visible-induced luminescence imaging. In Middleton, A., Uprichard, K., The Nebamun wall paintings, London, pp. 41-50 